\title{
Evaluation of Pharmaceuticals Sewage Effects on the Chemical Properties of Surrounding Surface Waters around Tehran
}

\author{
Mostafa Adelizadeh \\ PhD Student of Environment \\ Management \\ Department of Environmental \\ Education \\ Islamic Azad University, \\ Roodehen Branch, Tehran, \\ Iran
}

\author{
Nahid Rezaei \\ Faculty of Engineering \\ Department of Industrial \\ Engineering \\ Energy Institute of Higher \\ Educations, Saveh, Iran
}

\author{
Taher Taherian \\ Faculty of Engineering \\ Department of Industrial \\ Engineering \\ Energy Institute of Higher \\ Educations, Saveh, Iran
}

\begin{abstract}
This study investigates the effects of pharmaceutical industry sewage on effluent chemical characteristics of surrounding surface water in Tehran. The study was conducted using two in vitro methods and a method of environmental assessment. In vitro assessment and spatial analysis were conducted on inlet and outlet sewage of six pharmaceutical companies in different regions of Tehran. The results showed surveyed companies often use anaerobic treatment process method that reduces the environmental pollution, especially the reduction of negative effects on surface water around them.
\end{abstract}

\section{Keywords}

Pharmaceuticals, Tehran, Sewage, Assessment, Tests

\section{INTRODUCTION}

Iran's industrial growth faces different challenges and problems due to climatic characteristics, natural geographic features and potential limitations and capabilities. The importance of construction and development of the pharmaceutical industry on one hand, and the environmental consequences on the other hand has caused EPA to enact environmental laws and regulations for the industry. Predicting the potential consequences, this environmental management tool introduces actions in order to minimize the consequences determines strategies to improve environmental activities. Development of various pharmaceutical companies and industries in Tehran Province is especially necessary; accordingly, attention to the environmental impact is very important in positioning the industries. There various aspects of physical and ecological elements affected by consequences and effects of industry types in nature, among them effects on soil, water, air and the ecological features are of great importance. To maintain the quality of water resources needs more attention in arid environmental conditions such as Tehran Ellen (2006) [1], so that each cubic meter of untreated sewage can contaminate about 50 cubic meters of water. Therefore, if the underlying action is not taken to control industrial effluent, Tehran water resources are seriously threatened. However, no action can be absolutely pollution free, the important point is to find appropriate solutions to reduce and control pollution caused by such activities. Accordingly, impact assessment of industrial sewage seems more important. Given that, many chemicals are used in the pharmaceutical industry, in the absence of careful planning and management, this may lead to surface water pollution.
This paper studies pharmaceuticals sewage effects on the surrounding surface water in Tehran. Tehran is selected because the highest concentration of pharmaceutical industry (over 20 Pharmaceutical Factory) is located in this province. Moreover, Tehran seems more in need of assessments of its industry due to high population and environmental exposure sensitivity. This study aims to:

- Pharmaceuticals chemical effluent properties recognition from surface water quality standards

- Pharmaceuticals chemical effluent main effects on surface water resources introduction

- Tehran province pharmaceuticals chemical effluent effects on surface water resources

- provide effective solutions to the pharmaceutical industry positioning

Sidhu et al (2013) [2] in a study titled "sewage pollution in urban storm water runoff as evident from the widespread presence of multiple microbial and chemical source tracking markers" of human sewage contamination sewage in urban surface runoff $(\mathrm{N}=23)$ studied markers six urban basins areas throughout Australia using both Microbial Source Tracking (MST) and Chemical Source Tracking (CST). Also, they concluded that enteric viruses presently may exist in surface sewage samples pose significant health risks. Harisson et al (2006) [1] in a study titled "Organic chemicals in sewage sludge" showed that PAHs are most at risk for certain classes of chemicals, such as pesticides. Concentration due to sludge in the soil is a function of the initial concentration in the sludge and soil, application rates, and management practices. Presently, chemicals in high concentrations cause concentrations in soil. The results of this work needs to assess organic chemical pollutants in the sewage sludge. Santos et al (2010) [3] in a study titled "Ecological toxicity aspects related to the presence of pharmaceuticals in the aquatic environment" indicate that chemical contaminants may have impact on live organisms, ecosystems and ultimately negative impact on public health .Topp et al (2010) [4] in a study titled "Runoff of pharmaceuticals and personal care products under bio solid use in agriculture" show that Ibuprofen medicines, Acetaminophen, Carbamazepine, Cotinine, Gemfibrozil, Naproxen, Sulfamethoxazole and Triclosan concentrations first reduced in runoff and then increased; primarily in the form of slurry bio solids chemicals are physically and or 
chemically isolated, and then are released in the soil. Generally, this study showed that bio solids slurry injection below the soil surface can effectively eliminate surface runoff. Gunnarsdottir et al (2013) [5] in a study titled "Study sewage available at the North Pole pointing to drugs and personal care products (PPCPs) and Microbial Contamination" concluded that the sewage may contain bacteria resistant to antibiotics and pathogens that can have negative effects on human health and the environment in the Arctic; especially uncontrolled sewage may have very serious consequences for the environment. Gonzales et al (2012) [6] in a study titled "the presence and effects of emerging biological contaminants in Llobregat river basin" studied presence of emerging contaminants released during recent decades, with emphasis on the effect on ecosystems caused by pollution. Pesticides, surfactants, estrogens, pharmaceuticals and personal care products, and even drug abuse are major groups identified in various studies that report the changes in the species composition, the frequency or biomass as well as endocrine glands under the influence of enzymatic activity or the production of specific proteins. Stuart et al (2012) [7] in a study titled "Evaluation of the potential risk of emerging contaminants in groundwater in England," concluded that nanomaterials, pesticides, pharmaceuticals, industrial products and personal care products are flame and surfactant material resistant. Many of them are small polar molecules, which may not effectively be removed with water treatment and penetrate groundwater causing toxicity and potential risks for drinking water as well as the environment. Chamorro et al (2013) [8] in a study titled "Chemical properties of Micro-pollutants organic sources and biological effects in river sediments affected by sewage and paper mill discharges" using gas chromatography concluded that estrogenic and dioxins activity in sediments are often impacted by domestic sewage treatment plants. Patrick et al, in a study titled " Excretion and toxicity of pharmaceutical and personal care products in the environment " with the presence and fate of pharmaceuticals and personal care products (PPCPs) in the environment of a clinical pharmacokinetic and pharmacodynamics data for 81 common compounds signs of toxicity concluded that the rejection ratio of 60 compounds is $74 \%$. Carlsson et al (2006) [9] in a study titled " Are the strong medications environmental pollutants? part II: evaluation of the environmental hazards of pharmaceutical excipients selected" by examining five components used in pharmaceutical products for risk assessment environmental hazards using EUSES model and Docusate sodium indicator found that with an increase in the concentration of toxic substances Docusate sodium precipitated in organisms. Brain et al (2006) [10] in a study titled "Assessment of possible ecological risks: for example, to investigate drugs effects on aquatic plants" with CTDs analysis showed toxicity of EC10 gibba Lemna and EC25 showing that exposure with an antibiotic toxicity than $1 \%$ is less than $1 \mathrm{mg} / \mathrm{L}$. IESDs. A. Wei. Kelemes (2007) [11] in a study titled " Pharmaceuticals analysis in the environment Assessment" found that identifying particular features of pharmaceuticals better we can be informed of environmental pollution caused by them to have a more accurate assessment and management. Verlicci et al (2012) [12] in a study titled "Occurrence of pharmaceutical compounds in urban sewage: removal, mass load, environmental risk of secondary review"; most of the secondary sewage are related to antihypertensive medications, and several beta-blockers and painkillers and anti-inflammatory medicines. While, the greatest threat relates to antibiotics, drugs for psychiatric, analgesic and anti- inflammatory medicines.

\section{LITERATURE REVIEW \\ 2.1 Industrial Sewage}

BOD (Biochemical Oxygen Demand): a sewage BOD or water is the oxygen needs by microorganisms in the biochemical oxidation of organic matter. BOD actually determines the amount of oxygen required for the biological stability of organic matter samples. If BOD is about $1 \mathrm{mg}$ per liter, water is good and when gets about 3 , water is distrustful and in more than 5 , it is infected. COD amount is usually measured using a strong oxidizing agent in an acidic environment. BOD determination though has great value is associated with two fundamental shortcomings. The first is the long duration of trial and the second is possibility of poisoning microorganisms in contact with contaminated materials in a long time, so COD will be of great value.

\subsection{Sewage Classification}

Sewage is graded based on the amount of BOD. Sewage with BOD amounts of 210,350 , and $600 \mathrm{mlg} / \mathrm{lit}$ are weak, medium and strong sewage, respectively. To prevent water pollution in many parts of the world, no sewage treated with BOD more than $20 \mathrm{mg}$ per liter is not allowed to enter streams, surface or underground.

\subsection{Indiscriminate Discharge of Industrial Sewage in Surface Waters}

Excess drain water and industrial effluents (as well as nonindustrial and agricultural) in surface waters can cause aquatic animals, especially fish death. Interestingly, in addition the animal's corpses decomposing can pollute more. Another important effect of the disaster is the transformation of aerobic bacteria activities associated with oxygen consumption to anaerobic conditions without the need of oxygen. Activity of anaerobic bacteria is associated with the emergence of unpleasant odor and objectionable material, so that has the repulsive odor and is flammable. has a malodorous smell like rotten eggs and is toxic, and is a dangerous toxin and gives pungent smell of garlic. In general, most of anaerobic bacterial activity products are harmful for other living organisms, especially aquatic organisms.

\subsection{Chemicals and Industrial Sewage}

Detergents are most known chemicals used on a wide scale and caused contamination in a variety of reasons. From about 1940, synthetic detergents entered the consumer market; most important one was Alkyl benzene sulfonate. This kind of detergent has a major shortcoming that is the lack of decomposition by microorganisms. Presence of this material in water produces foam and the foam causes many problems for the operation of the treatment plant and also hinders photosynthesis. The use of detergents was later banned in America and Europe until 1965, with the new detergent LAS come to market that does not have the shortcoming and is being decomposed by microorganisms. Nitrogen compounds, particularly fertilizers are also entering the sewage system. Phosphorus and nitrogen enter into the lake water from the sewage and due to good feed to aquatic plants generates a phenomenon called aging. The lakes depth is reduced by deposits of mud and silt and one of the most important adverse effects of this phenomenon, which leads to a sharp decline in oxygen content of aquatic environment, is the transformation of aerobic bacteria into anaerobic ones. 


\section{MATERIALS AND METHODS}

According to research questions and an overview of the background investigations, the answers can be expressed as the following hypothesis:

- Pharmaceutical industries sewage has greater impact on the values of $\mathrm{PH}$ and $\mathrm{DO}$ of water.

- It is necessary to pay close attention to stay away from still and surface water when locating pharmaceutical industries production lines.

This study is based on sewage sampling of pharmaceutical industry in Tehran province. The sampling was done in two stages of before and after sewage treatment. Samples are analyzed by HPLC tools. Also, different criteria in the industry localization and their effects are taken into consideration. At this stage the higher potent of geographic information system (GIS) spatial analysis is used. Also in the process of research, samples were taken from plant sewage and laboratory works are considered in information extraction. Study data have been collected using sample sewage from pharmaceutical company's sewage treatment systems. Then, login Geographical coordinates of various companies in the ARCMAP software various maps have been achieved. The physic-chemical parameters including (BOD, COD, TSS, TDS, PH, T, Tur, Color, EC, Sal,) are measured using COD meter, BOD meter, EC meter, PH meter, flowmeter Apparatus and HPLC sewage inlet and outlet of the sewage treatment system is analyzed in the next step. Location of companies in regard to various environmental parameters is also studied entering the geographical coordinates of pharmaceutical companies in the ARCMAP software environment and use Tehran province geographic maps. First slope map is provided by ARCMAP software using DEM map. Then, maps of rivers, waterways, soil types, land use within Tehran pharmaceutical company's area is prepared and analyzed.

\section{RESULTS}

\subsection{Sewage Treatment Processes in}

\section{Pharmaceutical Companies with Sewage} Physicochemical Experiments Sewage

\section{Treatment in F Company}

First, inlet sewage enters into the anaerobic pool and then the aerobic pool. Later on pool overflow enters precipitation pool and then enters into final pool through a secondary process of treatment and finally, is used to irrigate plant green landscaping.

The results indicate that $\mathrm{F}$ sewage treatment system works fairly well because sewage treatment systems outlet is neutral but with high TDS and EC.

Table 1 - Experiments on Sewage Generated from Production Washing

\begin{tabular}{|c|c|c|c|c|c|}
\hline 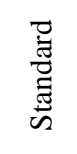 & 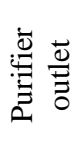 & 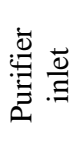 & 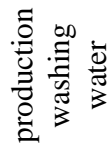 & $\begin{array}{l}\frac{\dot{d}}{\pi} \\
\frac{3}{3} \\
\overline{0} \\
3\end{array}$ & 总 \\
\hline $6-8.5$ & 9.1 & 8.04 & 7.6 & 7.6 & $\mathrm{PH}$ \\
\hline- & 1414 & 488 & 1013 & 1202 & TDS \\
\hline- & 1460 & 507 & 1049 & 1253 & $\mathrm{EC}$ \\
\hline
\end{tabular}

\section{Sewage treatment in B Company:}

first the sewage is DE rubbished, and then ferric chloride is added and mixed in a pool, filtered and enters anaerobic pool, later after color is added to it enters aeration and precipitation pools and finally treated sewage is used for irrigation.

Table 2 - Experiments on sewage generated from production washing

\begin{tabular}{|c|c|c|c|c|c|}
\hline 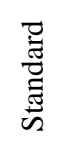 & 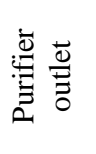 & 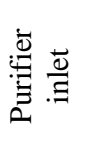 & 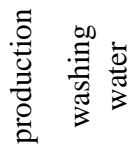 & 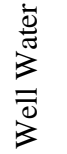 & 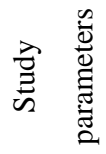 \\
\hline $6-8.5$ & 10.44 & 2.88 & 8.88 & 9.39 & PH \\
\hline- & 1933 & - & 9 & 416 & TDS \\
\hline- & 2.03 & 17.99 & 9.3 & 431 & $\mathrm{EC}$ \\
\hline
\end{tabular}

Results of the above experiments indicate that B Company sewage treatment system works well because the water PH is basal and electrical conductivity and total dissolved solids are low. Moreover, biological and chemical oxygen demand as a sewage treatment system measuring performance criterion is normal.

\section{Sewage treatment in C Company:}

First, inlet sewage enters into the anaerobic pool and then the aerobic pool. Later on pool overflow enters precipitation pool and then aluminum sulfate and Sodium hydroxide are added and then enters into final pool through a secondary process of treatment and finally is used to irrigate plant green landscaping

Table 3 - Experiments on sewage from the sewage treatment system

\begin{tabular}{|c|c|c|c|c|c|c|c|}
\hline 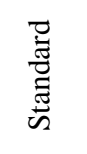 & 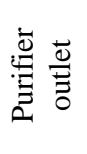 & 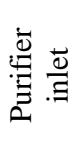 & $\begin{array}{l}\text { 。0 } \\
.0 \\
0 \\
0 \\
0 \\
0 \\
0 \\
0\end{array}$ & 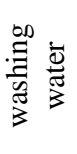 & $\begin{array}{l}\dot{\bar{d}} \\
\dot{\Xi} \\
\dot{3} \\
\bar{D} \\
\dot{3}\end{array}$ & 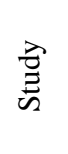 & 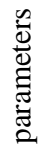 \\
\hline $6-8.5$ & 7.84 & 7.08 & 8.07 & & 9.23 & PH & \\
\hline- & 831 & 1014 & 487 & & 448 & TDS & \\
\hline - & 862 & 1060 & 506 & & 467 & EC & \\
\hline
\end{tabular}

Results of the above experiments indicate that C Company sewage treatment system works well because the water $\mathrm{PH}$ is basal and electrical conductivity and total dissolved solids are lowered. Moreover, biological and chemical oxygen demand as a sewage treatment system measuring performance criterion is normal.

\section{Sewage Treatment in a Company}

First, sewage enters into the initial pool where calcium oxide and aluminum sulfate is added to the pool in order to reduce acidity and increase calcium oxide. Then, in a pool with a high speed polymer material is added to it in for better deposition. Later on, enters chemicals pool and its overflow enters aeration pool, then biological pool and eventually enters into the river. 
Table 4 - Experiments on Sewage from the Sewage Treatment System

\begin{tabular}{|c|c|c|c|c|c|}
\hline 苞 & 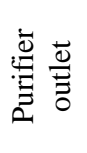 & 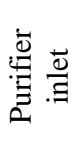 & 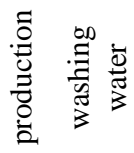 & $\begin{array}{l}\frac{1}{ \pm} \\
3 \\
\overline{3} \\
\overline{0} \\
3\end{array}$ & 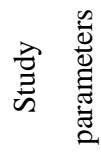 \\
\hline $6-8.5$ & 7.39 & 7.03 & 5.61 & 7.69 & $\mathrm{PH}$ \\
\hline - & 691 & 1012 & 292 & 963 & TDS \\
\hline- & 731 & 970 & 307 & 1012 & EC \\
\hline
\end{tabular}

Results of the above experiments indicate that A Company sewage treatment system works well because the water $\mathrm{PH}$ is basal and electrical conductivity and total dissolved solids are lowered. Moreover, biological and chemical oxygen demand as a sewage treatment system measuring performance criterion is normal.

\section{Sewage treatment in E Company:}

First the Sewage is DE Rubbished in initial pool, and then ferric chloride is added and enters into 4 anaerobic pools then mixed with 4 mixers, later on enters, aeration pool and poly aluminum chloride is added to it then enters precipitation pool and filtered through sand filters (to clear up particles), then color is added and enters final pool and stays there for a while (elimination of syringes and dish washing), sewage finally enters the finial pool contain sludges and then follows the treatment process. Results of the above experiments indicate that E Company sewage treatment system works well because the water PH is basal and electrical conductivity and total dissolved solids are lowered. Moreover, biological and chemical oxygen demand as a sewage treatment system measuring performance criterion is normal. Results show that heavy metal concentration in E Company sewage is more than limits and the sewage treated finally is used for irrigation of the plant green landscape

Results of the experiments indicate that E Company sewage treatment system works well because the water PH is basal and electrical conductivity and total dissolved solids are lowered.

Table 5 - Experiments on Sewage from the Sewage Treatment system

\begin{tabular}{|c|c|c|c|c|c|}
\hline 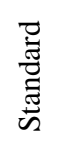 & 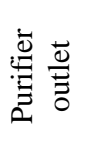 & 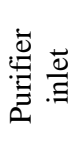 & 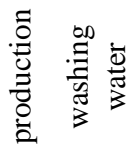 & $\begin{array}{l}\overline{0} \\
\frac{\pi}{3} \\
\overline{0} \\
3\end{array}$ & 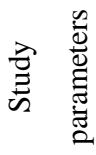 \\
\hline $6-8.5$ & 8.5 & 9.32 & 11.38 & 9.3 & $\mathrm{PH}$ \\
\hline - & 1044 & 845 & 628 & 495 & TDS \\
\hline - & 1085 & 890 & 650 & 515 & EC \\
\hline
\end{tabular}

\section{Sewage Treatment in D Company}

The sewage collected from different parts of the plant enter into the tank to be mixed in the steady state, Then, through the pump, the sewage enters into the sewage treatment system. Later enters open anaerobic pool and then enters closed anaerobic pools numbers $1,2,3$, and 4. In these pools, activated sludge and anaerobic bacteria break down organic matter in sewage and or in other words, fermentation and decomposition of organic matter occur; in this phase $\mathrm{H} 2 \mathrm{~S}$ and $\mathrm{CH} 4$ are also produced. After, the sewage enters the aeration pool to increase oxygen content in the sewage to boost aerobic bacteria activity. The bacteria begin activity in the presence of oxygen and continue sewage treatment cycle. After primary and secondary aeration, the sewage enters the precipitation pool where sewage sludge deposits and smooth and clear effluent enters chlorinator pool to remove germs and Then enters the sand filtration pool to eliminate suspended and colloidal solids then the treated sewage is pumped out to irrigate trees.

Results of the experiments indicate that E Company sewage treatment system works well because the water $\mathrm{PH}$ is basal and electrical conductivity and total dissolved solids are lowered. Moreover, biological and chemical oxygen demand as a sewage treatment system measuring performance criterion is normal with no adverse environmental impact on surface water quality

Table 6 - Experiments on Sewage from the Sewage Treatment System

\begin{tabular}{|c|c|c|c|c|c|}
\hline 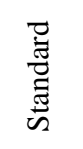 & 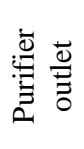 & 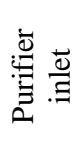 & 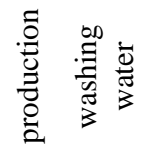 & $\begin{array}{l}\dot{\bar{\theta}} \\
\bar{\pi} \\
\bar{z} \\
\overline{0} \\
3\end{array}$ & 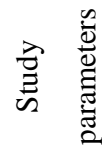 \\
\hline $6-8.5$ & 8.19 & 7.03 & 5.61 & 7.69 & $\mathrm{PH}$ \\
\hline- & 975 & 1012 & 292 & 963 & TDS \\
\hline- & 1016 & 970 & 307 & 1012 & EC \\
\hline
\end{tabular}

\subsection{Comparative Experiments of Inlet Sewage into the Sewage Treatment System}

In the following experiments, the inlet and outlet of sewage treatment systems are compared and analyzed.

Table 7 - Experiments on sewage from the sewage treatment system

\begin{tabular}{|c|c|c|c|c|c|c|c|}
\hline 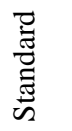 & D & E & A & C & B & $\mathrm{F}$ & 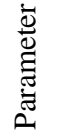 \\
\hline $6-8.5$ & 8.19 & 9.32 & 7.3 & 7.08 & 2.88 & 8.04 & $\mathrm{PH}$ \\
\hline - & 975 & 845 & 1012 & 1014 & - & 488 & TDS \\
\hline - & 1016 & 890 & 970 & 1060 & 17.99 & 507 & EC \\
\hline
\end{tabular}

Above experiment shows that B Company inlet sewage is more acidic and E Company inlet sewage is more basic. Moreover, the total dissolved solids are the most in $\mathrm{C}$ Company inlet sewage. $\mathrm{D}$ has the highest electrical conductivity than other pharmaceutical companies in observations. 
Table 8 - Experiments on sewage from the sewage treatment system

\begin{tabular}{|c|c|c|c|c|c|c|c|}
\hline 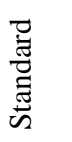 & D & E & A & $\mathrm{C}$ & B & F & 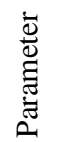 \\
\hline $6-8.5$ & 9.04 & 8.5 & 7.39 & 7.84 & 10.44 & 9.1 & PH \\
\hline- & 609 & 750 & 854 & 251 & 312 & 222 & TDS \\
\hline- & 931 & 1085 & 731 & 862 & 2.03 & 1460 & $\mathrm{EC}$ \\
\hline 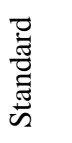 & D & E & A & $\mathrm{C}$ & B & $\mathrm{F}$ & 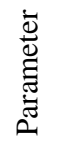 \\
\hline 100 & 44 & 74 & 30 & 15 & 59 & 68 & BOD \\
\hline 200 & 88 & 165 & 33 & 36 & 39 & 30 & COD \\
\hline 100 & 65 & 96 & 60 & 10 & 42 & 20 & TSS \\
\hline
\end{tabular}

Above experiment shows that outlet sewage from the sewage treatment system on C, E and A companies, are refined well, and so that acidity is normal based on experiments. Also, the total dissolved solids are the least in C Company and A has the lowest electrical conductivity than other pharmaceutical companies in observations. Moreover, according to experiments, the biological and chemical oxygen demand is normal for all pharmaceutical companies.

\subsection{The Environmental Status of}

\section{Pharmaceutical Companies Assessment}

In the next phase and after the review physicochemical properties of inlet and outlet sewage of treatment system, the environmental status of pharmaceutical companies is assessed. Accordingly, we find the geographical coordinates of pharmaceutical companies in Google Earth, then enter them into ARCMAP and locate them on Tehran city as well as Tehran Province with determining surrounding areas located at 200 and 1000 meters. According to environmental regulations and standards, this industry is allowed to be located outside city limits, subject to 100 meters compliance with residential, therapeutic, educational and military centers, rivers and police establishments. Compliance with all laws and regulations of the area is required. Most of the pharmaceutical industry is located in the metropolitan area in Tehran since at the time of construction and industry establishment there were no such criteria. These industries are located in incorrect positions. providing 200 and 1000 meter buffers, the location of the industries in adjacency to environmental locations is discussed.

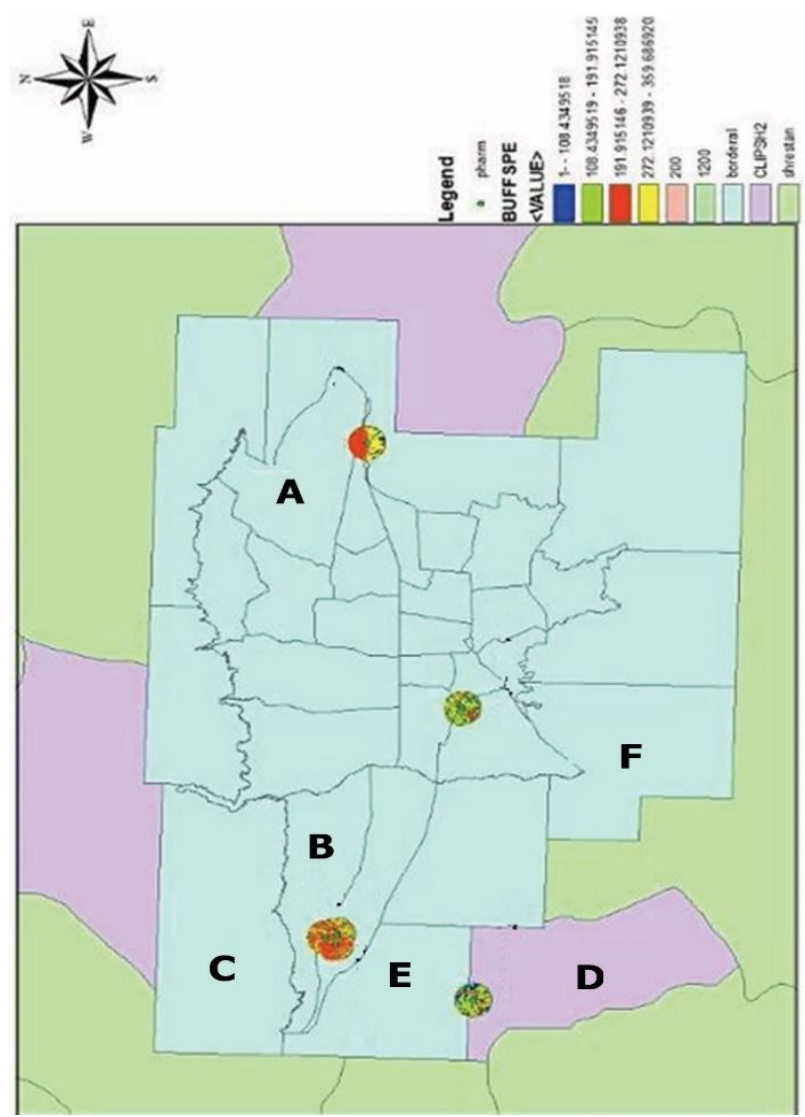

Fig 1: Geographical Map of Tehran Province Pharmaceutical Companies

Areas

The map above shows that the soil types of all pharmaceutical companies' areas are the same. D and F pharmaceutical company's geographical gradient is 89 degrees, and $\mathrm{A}, \mathrm{Cu}$ and $\mathrm{E}$ are geographically located at 90 degrees. F, B and E pharmaceutical companies are located at urban areas, D pharmaceutical company is located at agricultural land and C pharmaceutical company is located at crops land. There is a river in an area close to A pharmaceutical company, which requires closer attention regarding sewage management. Fortunately, the pharmaceutical company has a Sewage treatment system with high efficiency and environmentalists working in company continuously control sewage in terms of environmental pollution to prevent infection, especially to surface waters. The map above shows that more channels in Tehran are geographically located in the south in the areas of $\mathrm{D}$ and $\mathrm{F}$ pharmaceutical company that indicates more attention in the sewage control. Pharmaceutical companies, which are located in the metropolitan area of Tehran transfer environmental pollution (air, water, noise). A pharmaceutical company is close to a river, so this requires more careful management regarding sewage. The non-compliance with environmental and health standards on sewage treatment causes adverse effects on surface waters, especially rivers. 


\section{CONCLUSION}

Industries as one of the daily production tools and technologies cause a lot of harm to the environment during activities. One of the major damages is surrounding industries surface waters pollution. This study investigates the effects of pharmaceutical industry sewage on effluent chemical characteristics of surrounding surface water in Tehran. Two experimental and software methods were used in this study. In vitro, the inlet and outlet sewage samples were taken from the sewage treatment system and the physicochemical parameters were analyzed. Next, pharmaceutical industry status in terms of geographical and environmental parameters have been studied and analyzed to achieve more accurate assessment. The study findings indicate that pharmaceutical industry sewage has more effects on the amount of acidity, electrical conductivity, total dissolved solids and biological and chemical oxygen demand. Also in pharmaceutical industry locating, it is necessary to avoid surface and still water resources in the pharmaceutical industry production lines arrangements provisions.

\section{REFERENCES}

[1] Ellen, Z., Harrison, S., and Oakes, R., Hysell . M., and Hay.,A. 2006. Organic chemicals in sewage sludges, Science of The Total Environment, Volume 367, Issues 2-3, 31 481-497.

[2] Sidhu, W., Ahmed, W., Gernjak, R., Aryal, D., McCarthy, A., Palmer, P. and Kolotelo, S. 2013. Sewage pollution in urban stormwater runoff as evident from the widespread presence of multiple microbial and chemical source tracking markers, Science of The Total Environment, Volumes 463-464, 488-49637.

[3] Santos, L., Araújo, A., Fachini, A., Pena, C. and Matos, D .2012. Eco toxicological aspects related to the presence of pharmaceuticals in the aquatic environment, Journal of Hazardous Materials, Volume 175, Issues 1-3, 45-95.

[4] Topp, E., Monteiro, S., Beck, A., Coelho, B., Alistair B.A., Boxall, P.W., Kleywegt, S., David R. Payne, L., Sabourin, L., Li, H., Metcalfe, C.D.2008. Runoff of pharmaceuticals and personal care products following application of biosolids to an agricultural field, Science of The Total Environment, Volume 396, Issue 1, 52-5.

[5] Gunnarsdóttir, R., Jenssen, P.D., Jensen, P.E., Villumsen, A., and Kallenborn, R.2013. A review of sewage handling in the Arctic with special reference to pharmaceuticals and personal care products (PPCPs) and microbial pollution, Ecological Engineering, Volume 50, 76-85.

[6] González, S., López-Roldán, R., and Cortina, J.L. 2012. Presence and biological effects of emerging contaminants in Llobregat River basin: A review, Environmental Pollution, Volume 161, 83-92.

[7] Stuart, M., Lapworth, D., Crane, E., and Hart, A .2012. Review of risk from potential emerging contaminants in UK groundwater, Science of the Total Environment 416: $1-21$.

[8] Chamorro, V., Hernández, V., Matamoros, C. Domínguez, J., Becerra, G., Vidal, B., and Piña, J.M .2013. Chemical characterization of organic micro contaminant sources and biological effects in riverine sediments impacted by urban sewage and pulp mill discharges, Chemosphere, Volume 90, Issue 2, 611-619.

[9] Carlsson, C1., Johansson, A.K., Alvan, G., Bergman, K., and Kühler, T. 2016. Are pharmaceuticals potent environmental pollutants? Part II: environmental risk assessments of selected pharmaceutical excipients. The science of total environment. 364(1-3):88-95.

[10] Bryan, W., Richard, A., Duane, B., and Gerald, T. 2006. Risk assessment considerations for veterinary medicines in aquatic ecosystems. Veterinary Pharmaceuticals in the Environment. C14, pp 205-223.

[11] Klemeš, J. and Perry, S. J. 2007. Process optimization to minimize energy use and Process optimization to minimize water use and wastage, in Waldron $\mathrm{K}$ (ed.), Waste Management and Co-Product Recovery in Food Processing, 59-89, 90- 115 .

[12] Verlicchi, P., Al Aukidy, M., and Zambello, E.2012. Occurrence of pharmaceutical compounds in urban wastewater: removal, mass load and environmental risk after a secondary treatment--a review. The science of total environment. 429:123-55. 